Thorax (1964), 19, 68

\title{
Needle biopsy of the lung
}

\author{
With special reference to diffuse lung disease and the \\ use of a new needle ${ }^{1}$
}

\author{
W. G. S M I T H
}

From Sir Charles Gairdner Hospital (formerly Perth Chest Hospital), Western Australia

According to Scadding (1952) there are 83 causes of diffuse miliary or nodular shadows in the chest radiograph, some of which are manifestations of systemic diseases. It is hardly surprising that histological evidence is frequently necessary to make a definitive diagnosis. This may also apply to some localized lesions.

Biopsy material is usually obtained by thoracotomy. However, even the modified small thoracotomy of Klassen, Anlyan, and Curtis (1949) carries a definite morbidity and even mortality, especially in such diseases as carcinomatosis and diffuse pulmonary fibrosis. Some thoracic surgeons are loath to perform a diagnostic thoracotomy, a procedure which they feel is regarded too lightly by some of their medical colleagues. A satisfactory alternative might be some form of needle biopsy. It is the purpose of this paper to show that this can be done safely, simply, and swiftly, and will provide a positive histological diagnosis in many patients. It should be remembered that a thoracotomy biopsy is not always conclusive, and a repeat procedure is scarcely feasible as with needle biopsy. This is not to deny that thoracotomy will still be required for certain inaccessible lesions.

Needle biopsy can be broadly classed as aspiration and non-aspiration. Aspiration biopsy, using a syringe and needle, was first used by Leyden in Germany in 1883 to obtain bacteria in cases of pneumonia. Horder independently described the method in 1909. Aspiration biopsy became fairly popular in the decade 1930-40 (Craver and Binkley, 1939) until Ochsner and De Bakey (1942) condemned the procedure on the grounds of the possible spread of malignant and inflammatory lesions, although they did not document any proved cases. In recent years the aspiration technique seemed to be returning to favour (Gledhill, Spriggs and Binford, 1949). An aspiration biopsy is suitable for localized disease but is

1 This material was read at the August 1962 meeting of the Thoracic Society of Australia in Melbourne and the October 1963 meeting of the Royal Australasian College of Physicians in Brisbane. clearly far from ideal when dealing with diffuse lesions in a relatively elastic lung.

A more positive cutting action is provided by the Vim-Silverman needle (Fig. 1), first used to biopsy tumours by Silverman in the United States of America in 1938. A modification of this needle is fairly widely used to biopsy tumours, kidney, thyroid, liver, and pleura, but there are few reports of its use in lung biopsy. A paper from Cairo in 1960 reported 137 patients, of whom 120 had solid lesions, mainly carcinoma (Sabour, Osman, le Golvan and Ishak). Two other papers (Sarin and Bhatnagar, 1959 ; Miller, 1960) report 10 and nine patients respectively, of whom 16 had carcinoma. In these patients complications were few and comprised four small pneumothoraces, one large and two small haemoptyses, the former in a patient with pulmonary hypertension due to schistosomiasis. The surprisingly low incidence of pneumothoraces may reflect the large proportion of solid lesions, although the authors do not state whether all the patients had chest radiographs after the biopsy. Manfredi, Buckley, Patrick, Barry and Sieker (1960), in an experimental study with the Vim-Silverman needle in 22 dogs, stated that there were only two pneumothoraces in 88 biopsies.

My own experience with the Vim-Silverman needle dates from September 1961, and I have since used it on 39 patients, of whom 24 had diffuse lung disease.

\section{NEEDLE BIOPSY TECHNIQUE}

Premedication with an oral barbiturate and atropine, $0.6 \mathrm{mg}$. (1/100 gr.), is advisable. In diffuse lung disease the right lower lobe posteriorly has proved most satisfactory. A localized lung lesion is carefully defined by radiograph, with or without markers, and the needle is inserted accordingly. Six to eight millilitres of $1 \%$ lignocaine (Xylocaine) without adrenaline is infiltrated as far as the parietal pleura and followed by firm massage. ( $2 \%$ Lignocaine is unnecessary and potentially dangerous if a maximum dose of $10 \mathrm{ml}$. 
FIG. 1. The Vim-Silverman biopsy needle (slightly modified by hollow grinding of the blades).

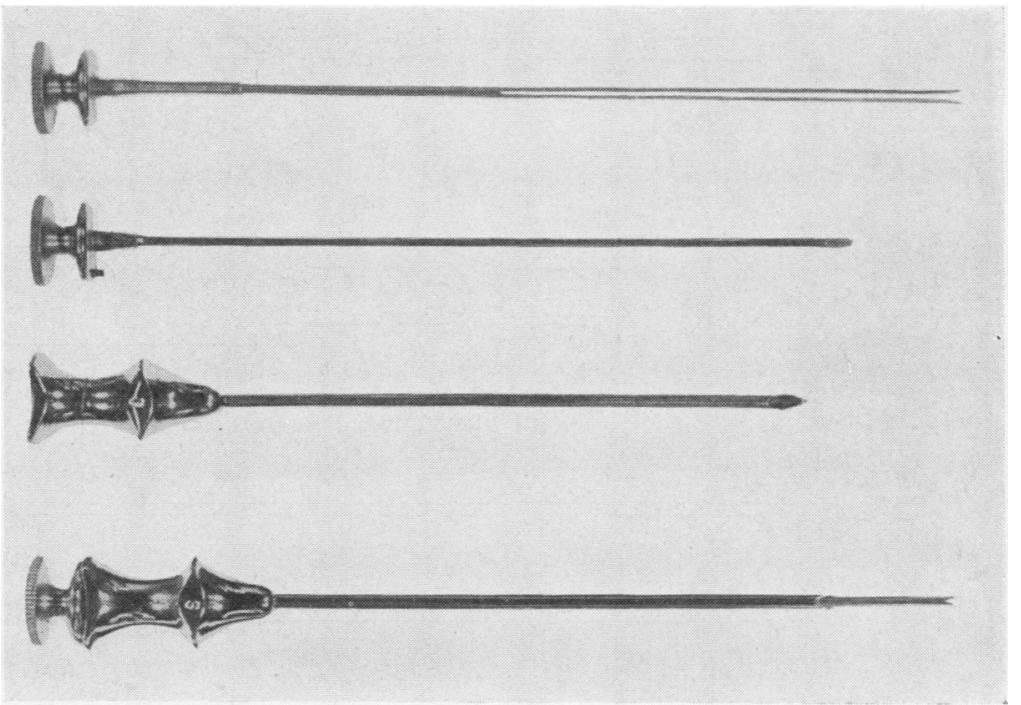

The punch consists basically of a 13 B.S.W. gauge needle tube (O.D. $2.4 \mathrm{~mm}$.) and a 16 B.S.W. gauge solid rod which can slide within the bore of the tube.

Figure $2 \mathrm{a}$ illustrates the complete assembled punch. (F) is a 13 gauge needle of length $7 \mathrm{~cm}$. The proximal end of the needle is welded into the handle $(\mathrm{H})$. The distal end is tapered, corresponding to the internal taper on a detachable cutting cannula (E). Figure 2c is an enlarged view showing the cannula taper fitted onto the needle, and it also illustrates the concave ground cutting edge $\left(E^{1}\right)$.

Figure $2 b$ illustrates part of the 16 gauge rod (D) which slides into the needle (F). The rod, $17 \mathrm{~cm}$. in length, is introduced into the cannula (E) and passes through the needle and handle $(\mathrm{H})$. The end of the rod is threaded to correspond with an internal thread on the adjusting nut $(\mathrm{J})$ and the locking nut $(\mathrm{K})$. Welded onto the proximal end of the rod is an obturator consisting of a trocar pointed tip (A), tissue snag (B), and plunger (C). The diameter of the tip (A) is slightly in excess of the outer diameter of the cannula (E). The rear of the tip (A) has a soft cutting surface for the approximation of the cutting edge $\left(E^{1}\right)$ of the cannula (E). The diameter of the plunger at $B$ and $C$ corresponds to the bore of the cannula (E). The plunger (C) provides the necessary stability for close approximation and reduces the likelihood of air leaks. Between A, B, and C the diameter is reduced to half to provide specimen snagging and retaining area.

In Fig. $2 \mathrm{a}$ the assembled punch is shown in the open position. Part of the obturator plunger and the snag protrude beyond the cannula. This projection is normally about 5 to $6 \mathrm{~mm}$. Adjustment is by means of nuts ( $J$ and $\mathbf{K})$. The punch is closed by holding the handle ( $H$ ) and drawing nut assembly ( $\mathrm{J}$ and $\mathrm{K}$ ) back, retracting the plunger and snag into the cannula bore, and approximating the rear of the tip (A) and the
The instrument (Fig. 2a) has been designed with the aim of reducing the size of the essential components to a minimum consistent with obtaining a satisfactory specimen. 
(a)

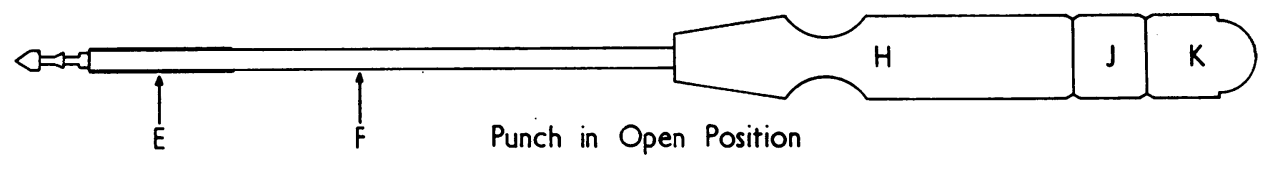

(b)

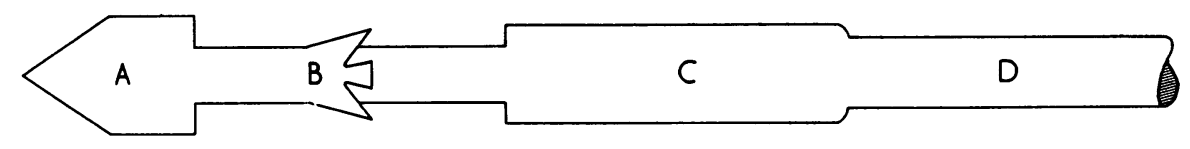

(c)

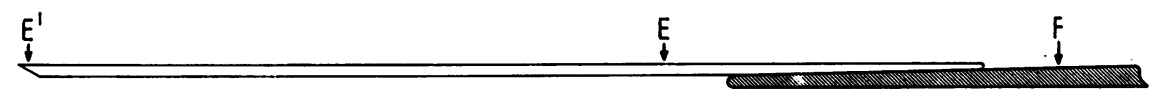

FIG. 2. The Jack needle. For details see text.

cutting edge $\left(E^{1}\right)$. The specimen is found attached to the snag (B) and cutting face of $A$.

An introducing skin trocar is supplied, which facilitates skin puncture and avoids the use of a scalpel blade.

STERILIZING It is suggested that a hot-air procedure is used in preference to steam when sterilizing this needle. The hot-air method will assist in preserving the cutting edges and enable the needle to be fully assembled and adjusted before being sterilized. An Alka syringe case, for example, is a satisfactory container method.

CUTTING CANNULA REPLACEMENT AND SHARPENING TECHNIQUE The stainless steel cutting cannula is taper fitted to the outer needle. A slight twisting action is necessary to detach the cannula from the needle (the use of forceps should be avoided). The cannula has a concave cutting edge which, although hardened, requires periodic sharpening. The edge can be easily restored by a lapping process. A lap is constructed from a piece of steel rod $5 \mathrm{~mm}$. in diameter ground at one end to an angle of $60^{\circ}$. A fine industrial grinding paste is applied to the conical lap face and the lap is then rotated lightly against the cutting edge of the cannula.

TECHNIQUE The earlier remarks regarding premedication and local anaesthesia are, of course, applicable.

Before use, the following adjustments should be checked. The punch should open 5 to $6 \mathrm{~mm}$. in the 'open' position. The domed lock nut should be firmly tightened against the adjusting nut. This ensures that the inner rod and trocar point can be held immobile while the outer cutting cannula is rotated against the softer anvil in the 'closed' position.
The closed needle is sharply advanced about 3 to $4 \mathrm{~cm}$. into the lung during held inspiration. The punch is then opened and the whole assembly withdrawn about $1.5 \mathrm{~cm}$. to ensure trapping a portion of lung on the snag. The punch is then sharply and firmly closed. While maintaining a firm pressure in this position, the inner rod is held immobile and the outer needle is rotated through an arc of $90^{\circ}$ in an oscillatory manner. (This manoeuvre is nzcessary to sever the tissue.) The needle is then quickly withdrawn, meantime firmly holding it in the closed position. A second attempt may occasionally be necessary, but this may fail if there is already a significant pneumothorax.

Speed and firmness of action are essential in the successful use of the needle. These can be readily achieved with a little practice on a block of plastic foam (Estafoam) or on an animal or cadaver lung. It should not be necessary for the needle to remain in the lung for more than five or six seconds, and the entire procedure takes less than 10 minutes.

\section{RESULTS}

Table I shows the results in the total series of 61 patients. Lung tissue was obtained in $79 \%$ of patients. A positive histological diagnosis was made in 39 patients (64\%). The complications in general have not been troublesome. There was no mortality: pneumothorax is the commonest complication and occurred in $41 \%$ of the patients. The majority of pneumothoraces were trivial. In four of the five moderate pneumothoraces and in the large pneumothorax an intercostal tube with underwater seal was inserted because of severe dyspnoea mainly due to the underlying lung 
T A B LE I

NEEDLE BIOPSY OF LUNG

3 September, 1961, to 31 December, 1962

\begin{tabular}{|c|c|c|c|}
\hline $\begin{array}{c}\text { Total number of patients } \\
\text { Diffuse disease } \\
\text { Local disease }\end{array}$ & $\begin{array}{l}\cdots \\
\cdots\end{array}$ & $\begin{array}{l}\dot{4} 1 \\
20\end{array}$ & 61 \\
\hline $\begin{array}{l}\text { Vim-Silverman needle } \\
\text { Jack needle }\end{array}$ & $\ddot{x}$ & $\begin{array}{l}. \\
\cdots\end{array}$ & $\begin{array}{l}39 \text { (11 failures } \\
22 \text { (1 failure) }\end{array}$ \\
\hline $\begin{array}{lll}\text { Lung tissue } & \ldots & \ldots \\
\text { Pleura only } & \ldots & \ldots \\
\text { No biopsy material } & \ldots\end{array}$ & $\begin{array}{l}\cdots \\
\cdots \\
\cdots\end{array}$ & $\begin{array}{l}\cdots \\
\cdots \\
\cdots\end{array}$ & $\begin{array}{l}48(79 \%) \\
6(10 \%) \\
7(11 \%)\end{array}$ \\
\hline Positive histological diagne & & .. & $39(64 \%)$ \\
\hline $\begin{array}{l}\text { iplications } \\
\text { Pneumothorax }\end{array}$ & $\cdots$ & . & $\begin{array}{l}25(41 \%) \\
19 \text { small } \\
5 \text { moderate } \\
1 \text { large }\end{array}$ \\
\hline Haemoptysis .. & . & $\cdots$ & 5 minimal \\
\hline $\begin{array}{l}\text { Post-biopsy pain } \\
\text { Subcutaneous emphysema } \\
\text { Vaso-vagal episode ... } \\
\text { Pulmonary haematoma }\end{array}$ & $\begin{array}{l}\cdots \\
\cdots\end{array}$ & $\begin{array}{l}\cdots \\
\cdots \\
\cdots\end{array}$ & $\begin{array}{l}3 \text { moderate } \\
3 \\
1\end{array}$ \\
\hline
\end{tabular}

disease (carcinomatosis, diffuse fibrosis, radiation fibrosis, and emphysema). Following insertion of the intercostal tube, rapid re-expansion of the lung occurred and the tubes were removed in two to four days in all but one of the five patients. The other patient had bullous emphysema and had a persistent air leak requiring suction by the intercostal tube for several days. The great majority of patients had no significant pain associated with the procedure. Three patients had moderate pain on the evening of the biopsy and two were given one injection of pethidine. One patient had fairly extensive subcutaneous emphysema, no doubt occasioned by adhesions at the site of the peripheral lung lesion as there was no significant pneumothorax. Four patients had haemoptyses. In two patients approximately two or three ounces of almost pure blood were coughed up during a 20-minute period after the biopsy. Two further

TABLE II NEEDLE BIOPSY OF LUNG IN 41 PATIENTS WITH DIFFUSE

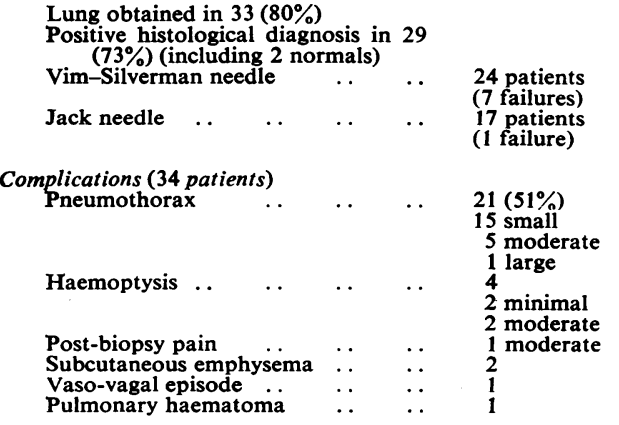

patients had slightly blood-streaked sputum on the evening of the biopsy. One patient had a probable haematoma which resolved in 72 hours, shown radiographically at the site of the biopsy. There were no apparent haemothoraces or infections, and there was no evidence of local spread of malignancy in the 15 patients with this disease.

The findings in 41 patients with diffuse lesions are shown in Table II. Lung tissue was obtained in $33(80 \%)$ and all but one of the eight failures occurred when using the Vim-Silverman needle. A positive histological diagnosis was made in 29 (73\%) including two normals. As expected, the incidence of pneuinothoraces was higher than with localized disease.

Table III shows the histological diagnosis in 29 patients. Brief details of a few of these patients may be of interest.

TABLE II I

NEEDLE BIOPSY (SF LUNG: POSITIVE HISTOLOGICAL DIAGNOSIS IN 27 PATIENTS WITH DIFFUSE DISEASE

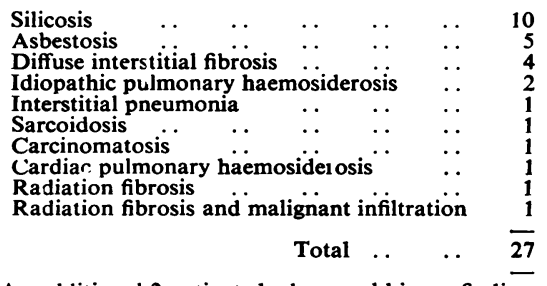

An additional 2 patients had normal biopsy findings.

\section{CASE REPORTS}

An Australian man aged 65 years had a chest radiograph showing numerous shadows strongly suggestive of malignancy. Needle biopsy showed squamous carcinoma (Fig. 3).

An Italian man aged 39 years, with a history of exposure to silica, developed a fine nodular pattern on the chest radiograph over a five-year period. Right upper lobe tuberculosis was diagnosed and treated during 1962. Needle biopsy of the right lower lobe showed classical silicosis (Fig. 4).

Another Italian man aged 52 years was admitted after a slight haemoptysis. He denied exposure to silica, although the chest radiograph was very suggestive. Needle biopsy showed advanced silicosis (Fig. 5). It later transpired that this patient was wilfully concealing a history of tunnelling in Italy.

A Polish man aged 39 years had been exposed to asbestos at Wittenoom Gorge. The chest radiograph showed a rather unusual appearance in that the upper lobes were densely fibrotic in addition to the generalized 'ground-glass' appearance of asbestosis. Sputum cultures were negative for tubercle bacilli, and needle biopsy showed the appearances of severe asbestosis without evidence of tuberculosis (Fig. 6). 


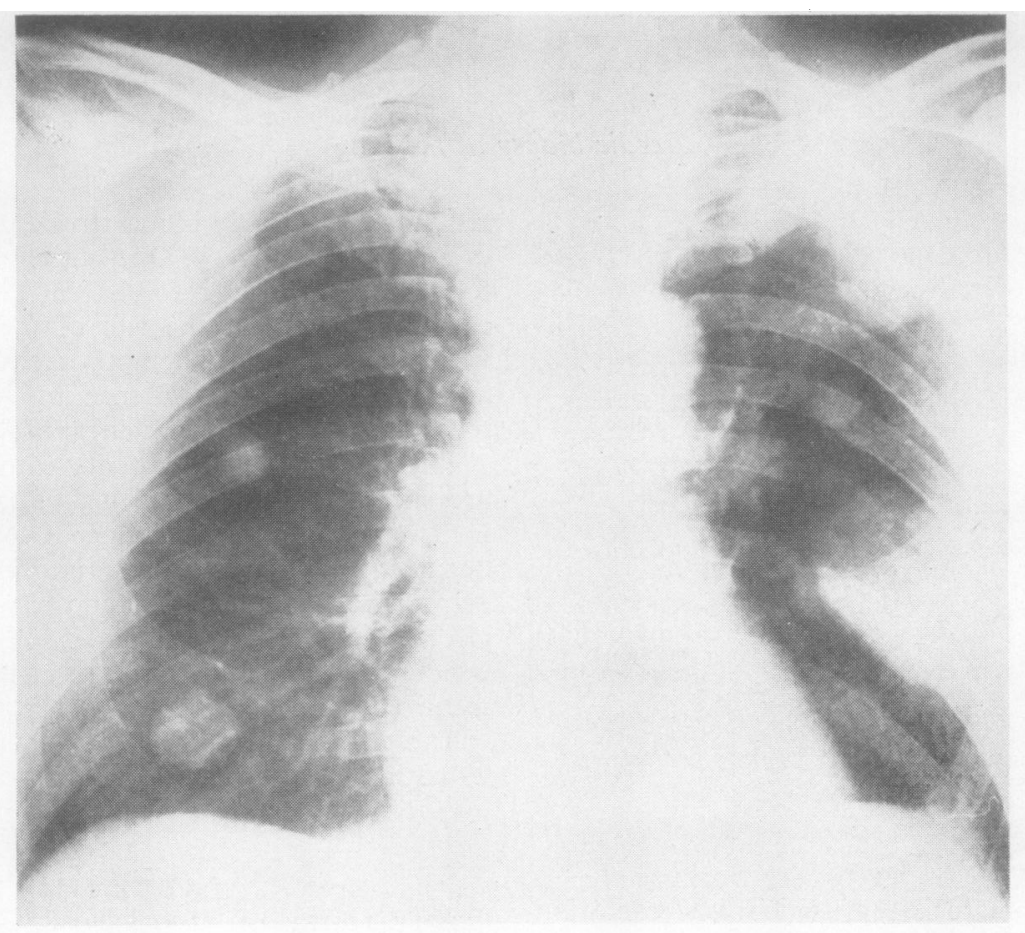

(a)

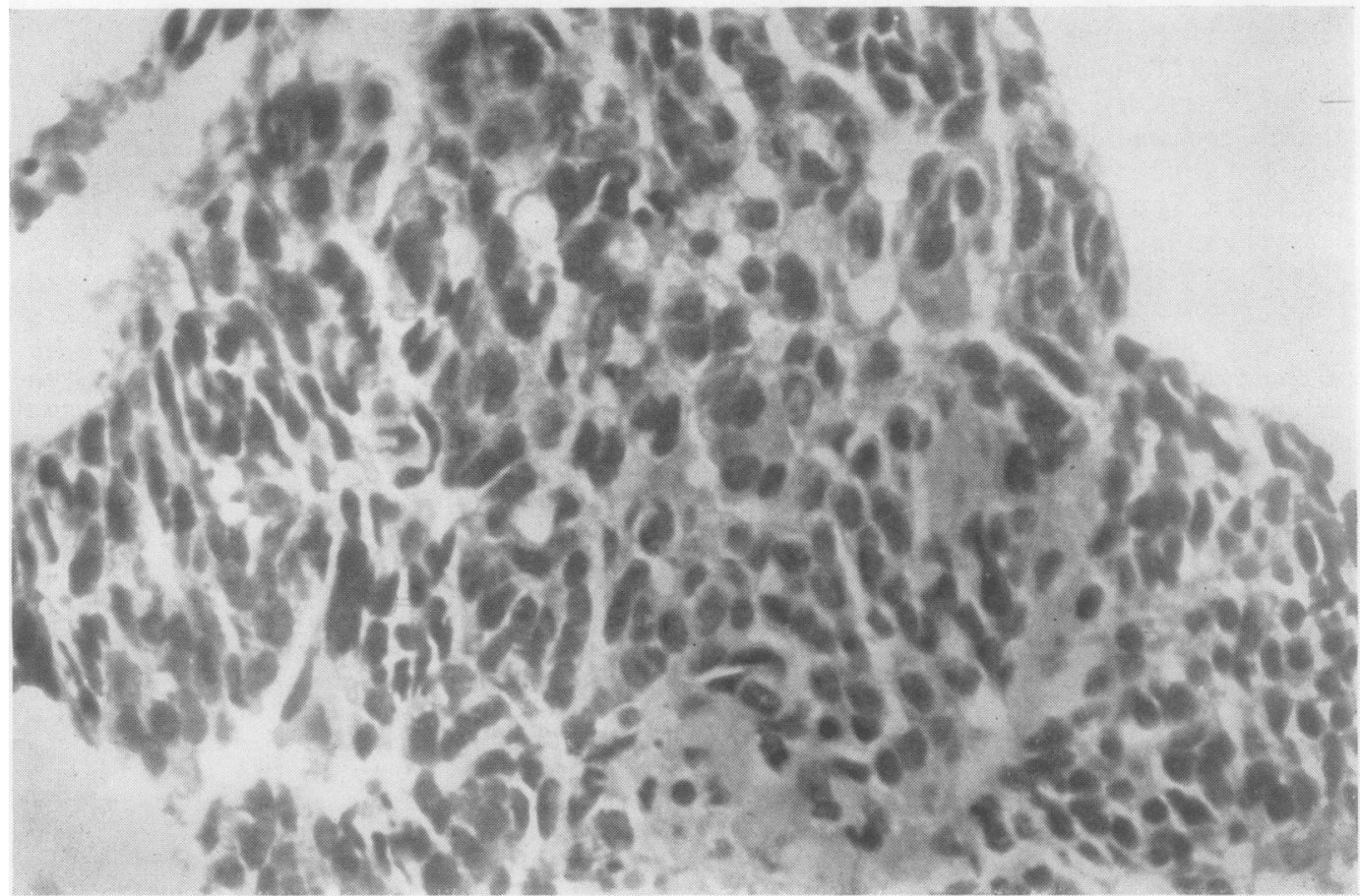

(b)

FIG. 3. (a) Radiograph and (b) needle biopsy of patient with diffuse carcinomatosis. 


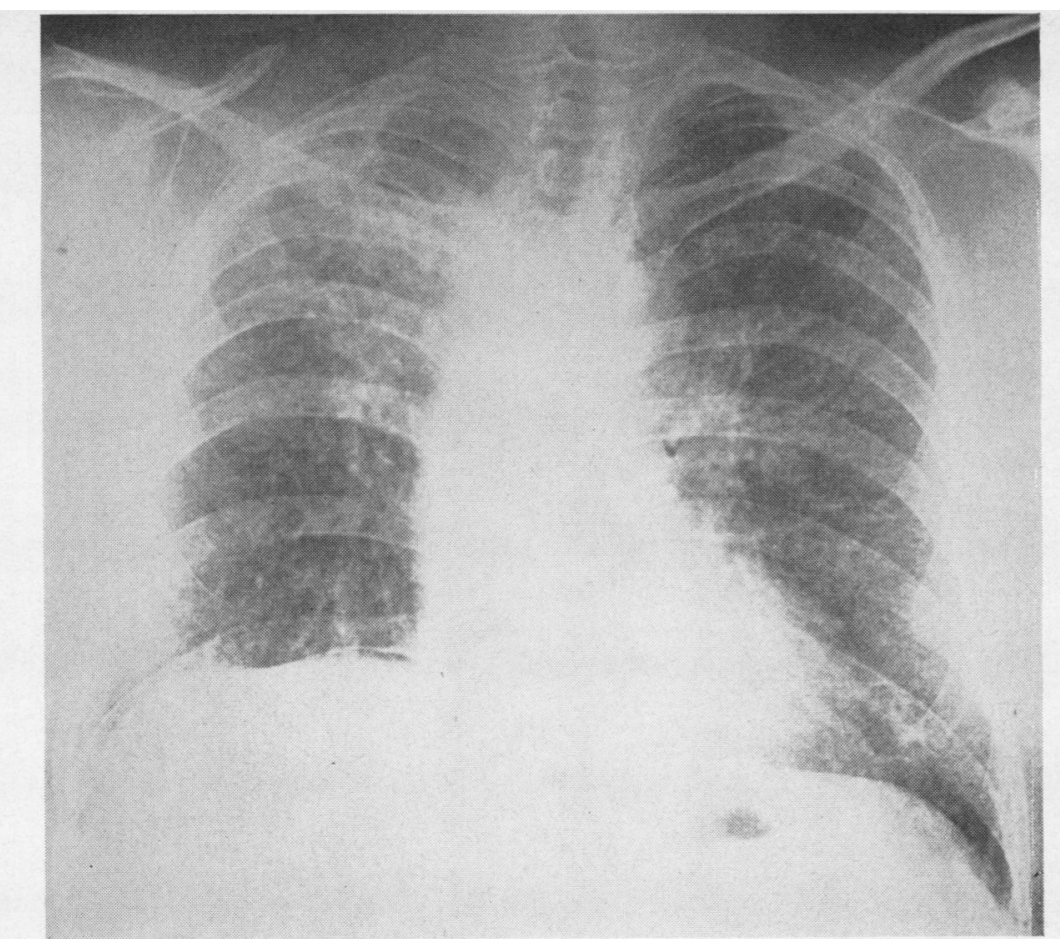

(a)

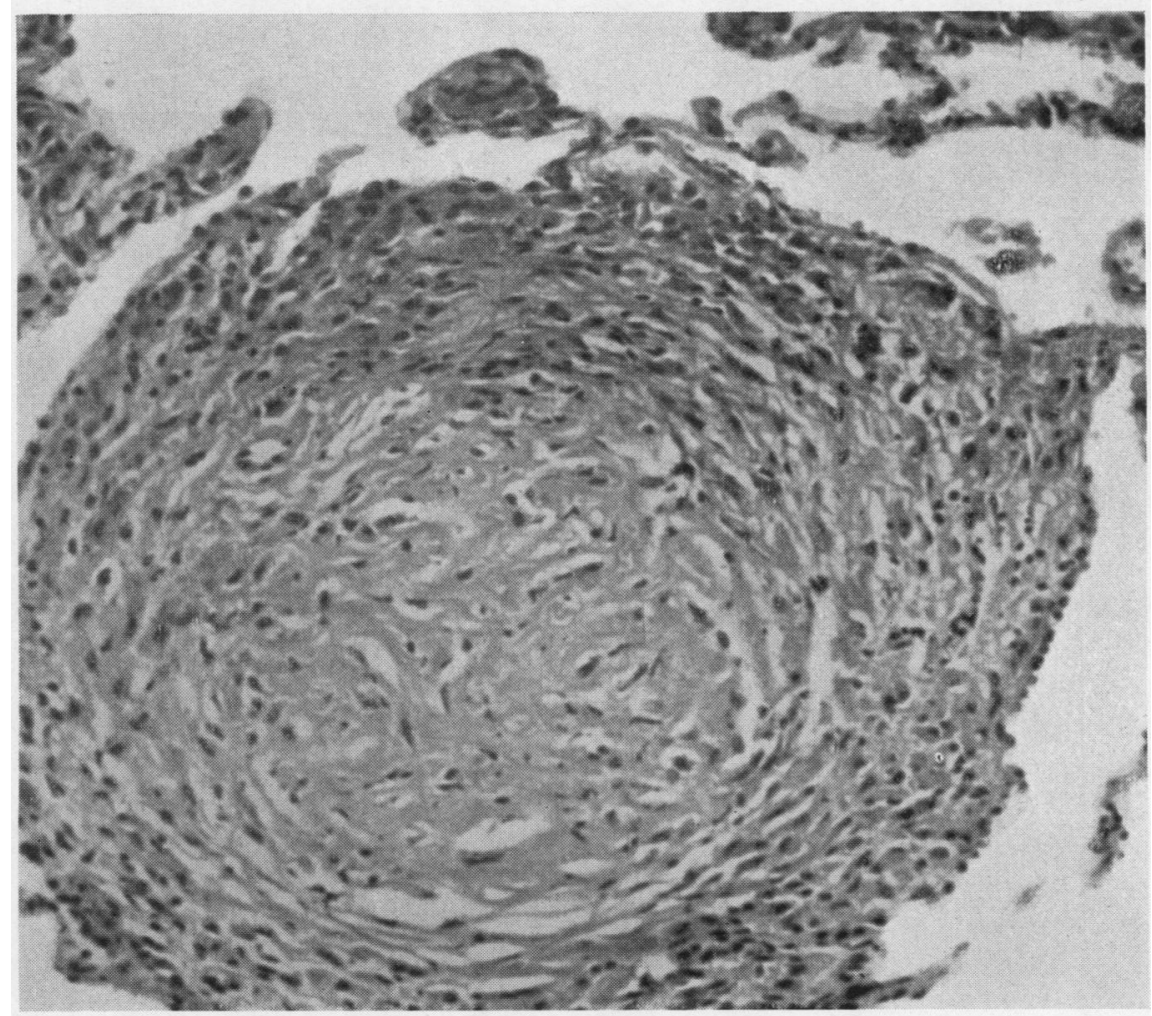

(b)

FIG. 4. (a) Radiograph of patient with silico-tuberculosis; (b) needle biopsy showing silicosis. Large numbers of doubly refractile crystals of silica were present in the whorled fibrous nodule. 


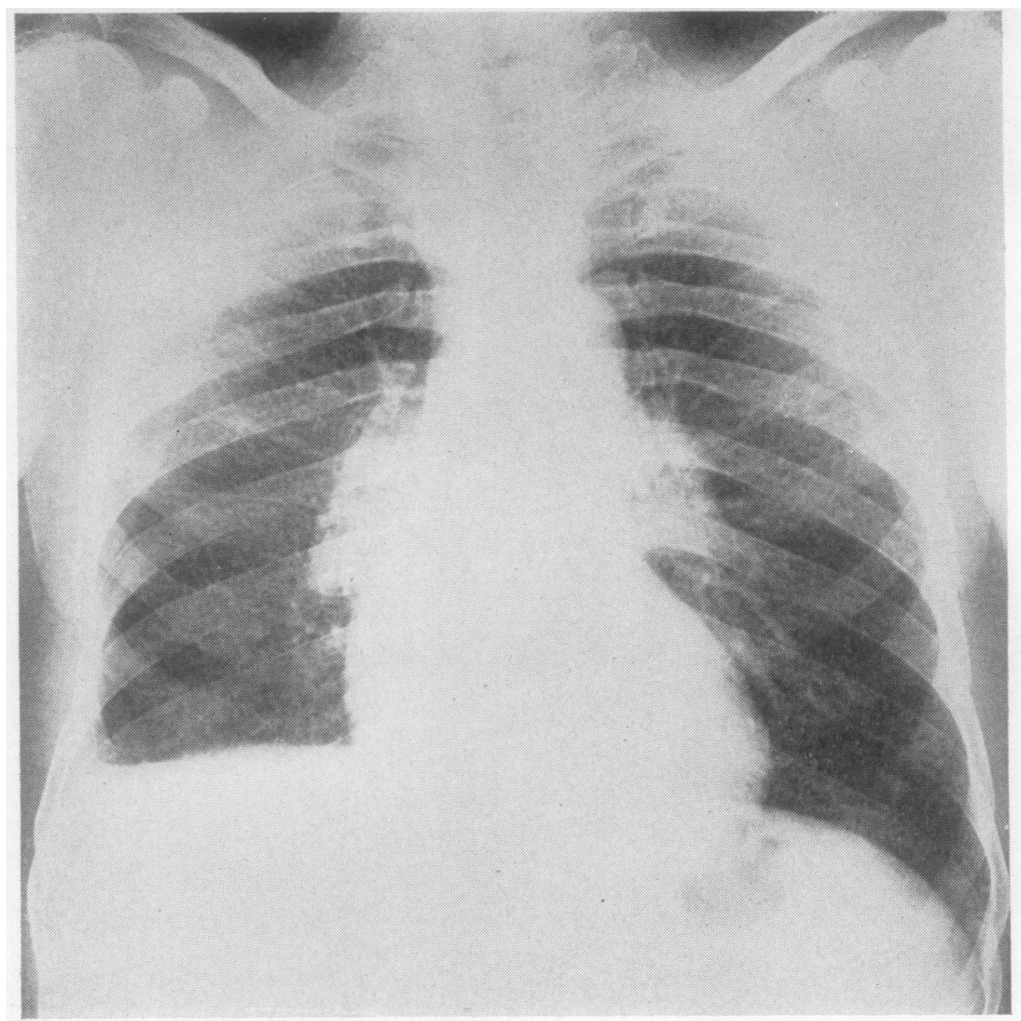

(a)



(b)

FIG. 5. (a) Radiograph of patient who denied exposure to silica; (b) needle biopsy showing doubly refractile crystals of silica amidst dense fibrosis. 


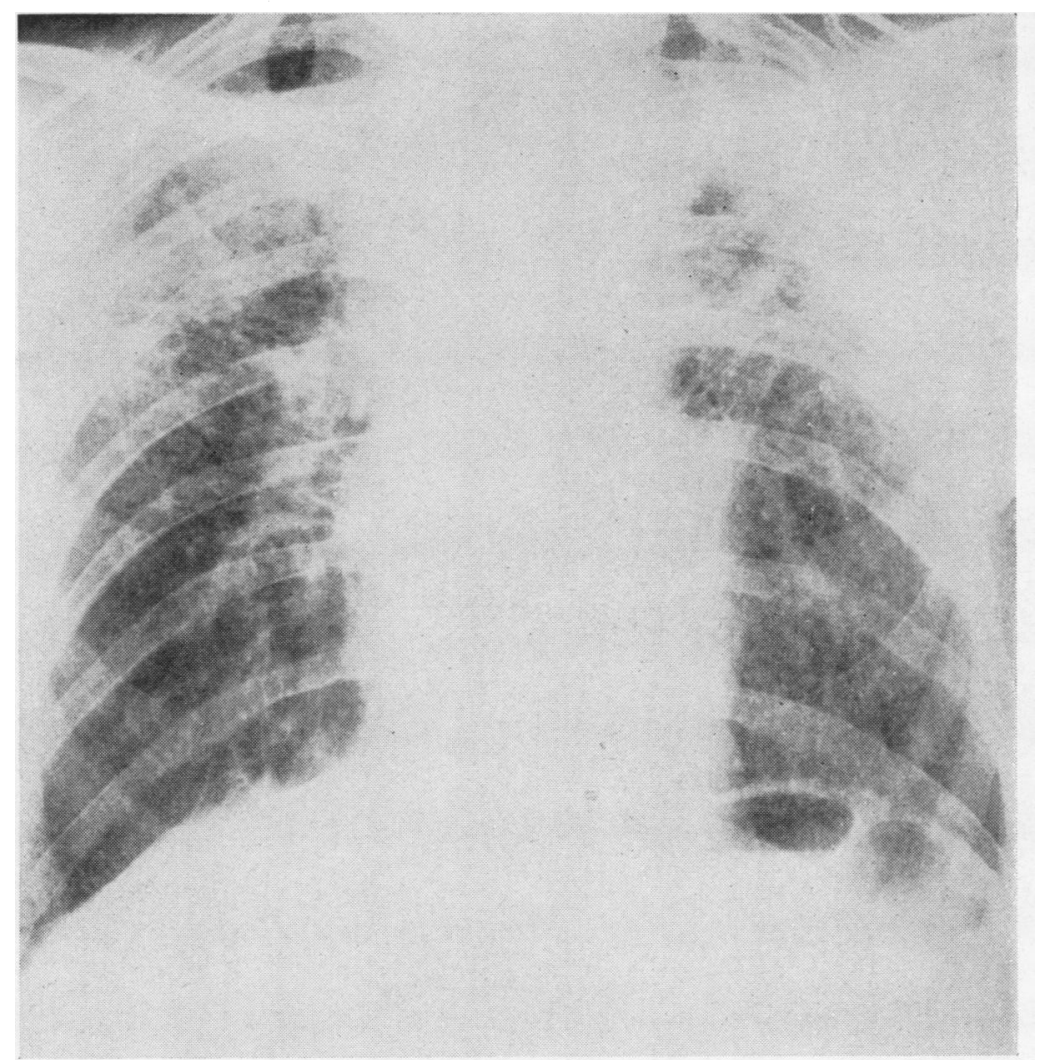

(a)

FIG. 6. (a) Radiograph of patient with asbestosis of unusual type; (b) needle biopsy showing asbestos bodies, cellular infiltration and dense fibrosis. 

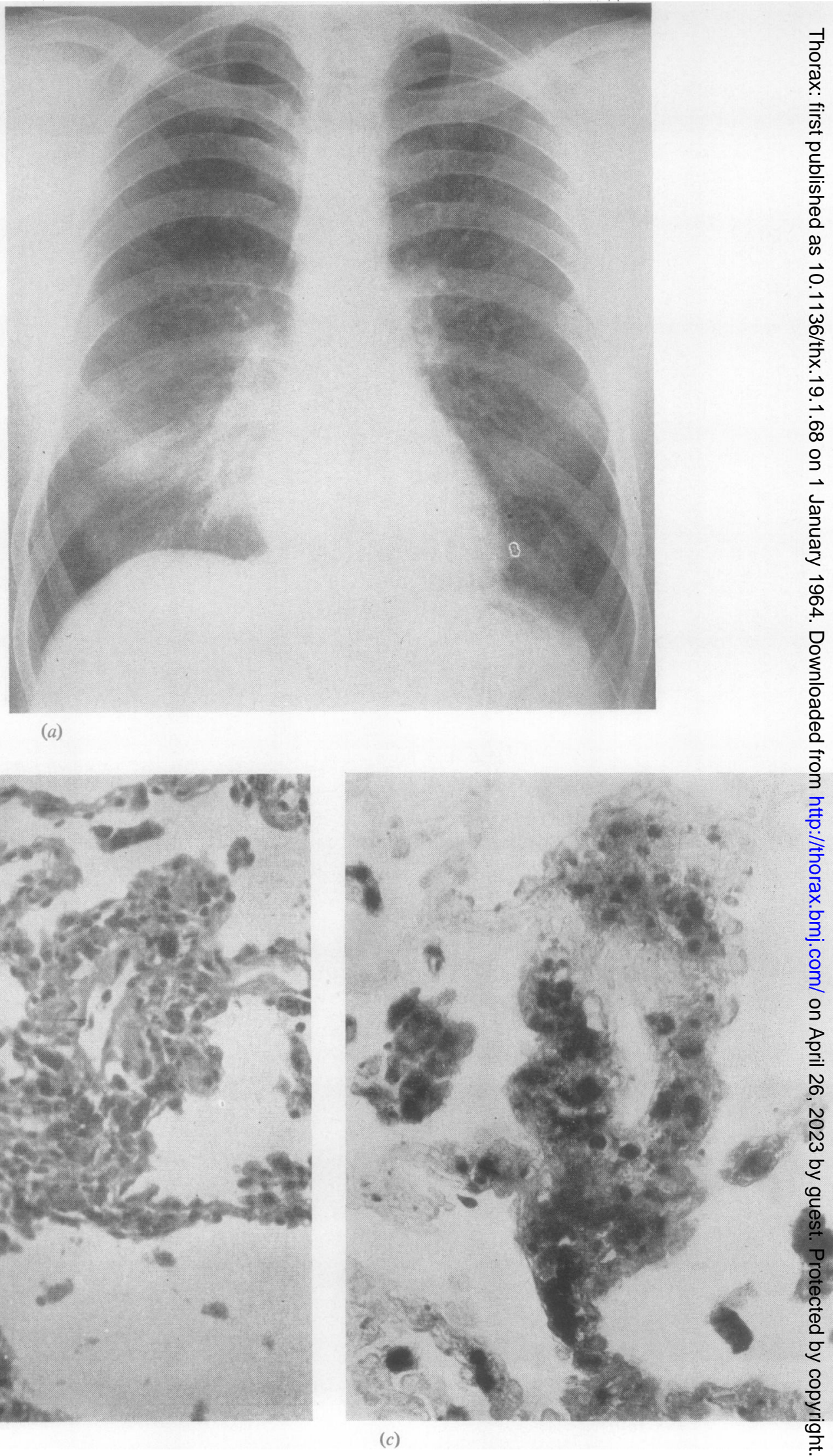

(a)

(b)

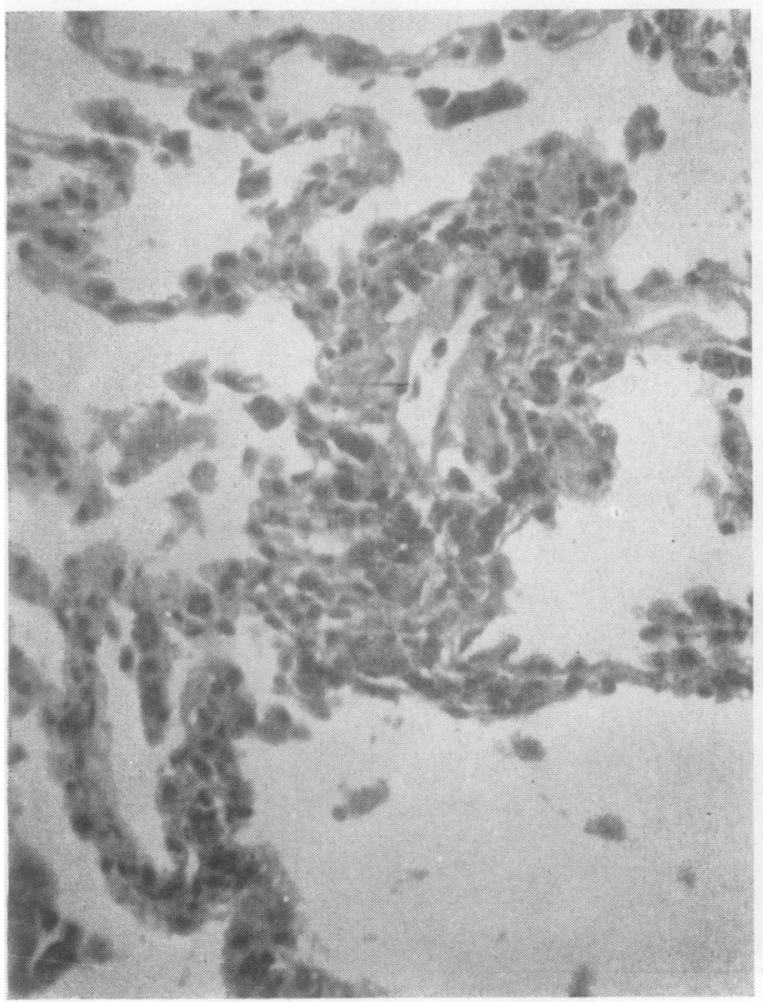

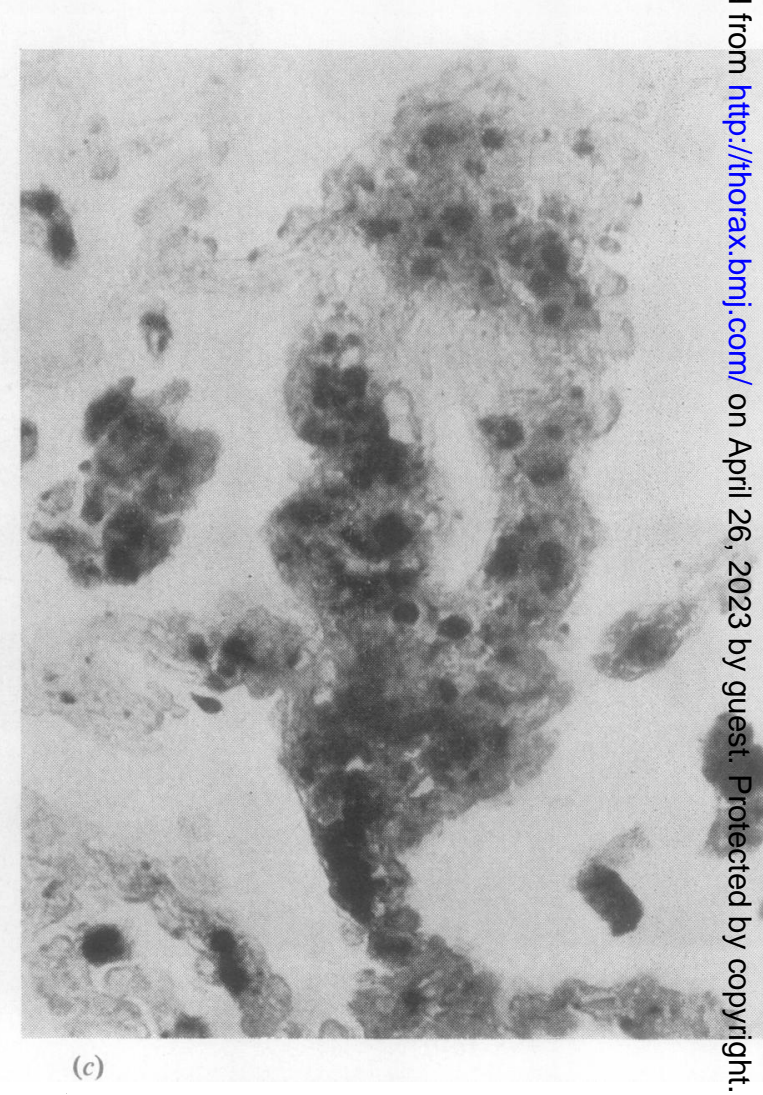

FIG. 7. (a) Radiograph of patient with diffuse pulmonary haemosiderosis (idiopathic); (b) needle biopsy showing appearances of diffuse pulmonary haemosiderosis; (c) needle biopsy stained for iron. Haemosiderin appears as dark material. 
An Australian man aged 30 years had a history of recurrent haemoptyses and anaemia. The clinical features and chest radiograph suggested diffuse idiopathic pulmonary haemosiderosis. This was confirmed by needle biopsy of both lower lobes (Fig. 7).

\section{INDICATIONS AND CONTRA-INDICATIONS}

Needle biopsy of the lung is mainly of use as an ancillary diagnostic aid. It may be indicated in the diagnosis of peripheral lung lesions, such as carcinoma and tuberculous and non-tuberculous infections. It is especially helpful in the diagnosis of diffuse lung disease, such as pneumoconiosis, carcinomatosis, diffuse interstitial fibrosis, haemosiderosis, and granulomatous and 'collagen' diseases. In compensation cases, a needle biopsy may well provide essential evidence so often lacking after study of the chest radiographs and occupational history. Needle biopsy may have a wider research application in obtaining lung tissue for histochemical, bacteriological, and viral study. Pulmonary hypertension may be a relative contraindication. Otherwise needle biopsy could provide important information in the study of the variou; types of pulmonary hypertension. In a patient with severe pulmonary hypertension (a girl with the Eisenmenger syndrome) blood was freely aspirated from the lung with the local anaesthetic needle and a biopsy was therefore not attempted. This experience and the Cairo report suggest that considerable bleeding could follow needle biopsy in severe pulmonary hypertension. Other contraindications are few and include an uncooperative patient (a general anaesthetic should solve this problem), bleeding diathesis, pulmonary arteriovenous fistula, cysts, bullae, and severe emphysema.

The procedure should be done in hospital with facilities for insertion of an intercostal tube or air aspiration from the pleural cavity. In this series all pneumothoraces were maximal within a few hours of the biopsy and there was no evidence of a delayed pneumothorax. There seems no reason therefore why the procedure should not be done on out-patients, provided the patient is observed for several hours and a chest radiograph is taken.

All needle biopsies are subject to the failing that the biopsy tissue may not be representative of the disease as a whole. If this is suspected, there need be no hesitation in advising a repeat biopsy.

\section{COMMENT}

There has been no evidence so far of untoward results, such as spread of malignancy or infection.
There is no mention of local spread of malignancy in the $120 \mathrm{Vim}$-Silverman biopsies of Sabour et al. (1960). It is suggested, however, that, where indicated, antibiotics or antituberculous chemotherapy should be initiated before biopsy.

The Jack needle is also well suited for biopsy of the pleura and possibly of other organs or tissues. It is smaller and easier to use than the conventional Abrams or Harefield punch biopsy needle (Abrams, 1958), and it can be safely used in the absence of pleural fluid. Its sole disadvantage in not allowing aspiration of fluid can be easily overcome by the use of a separate aspirating needle.

In several patients I have performed separate and immediately consecutive biopsies of the lung and parietal pleura. In one patient malignancy was revealed in the lung but not in the pleural specimen. The Abrams needle was specifically designed for pleural biopsy when a pleural effusion is present. It is inherently unsuitable and potentially dangerous for lung biopsy.

\section{SUMMARY}

A series of 61 patients, who have had needle biopsy of the lung, is described.

Needle biopsy of the lung is quick, relatively safe and easy, and is not unpleasant for the patient. A positive histological diagnosis was made in $64 \%$ of the whole series and $73 \%$ of the 41 patients with diffuse lung disease.

The main complication is pneumothorax (approximately $40 \%$ of the series) but this is seldom troublesome.

The Vim-Silverman needle is satisfactory for relatively solid peripheral lesions. The new Jack needle described in this paper is particularly suitable for the diagnosis of diffuse lung disease. It is equally satisfactory for pleural biopsies with or without associated pleural effusion.

The relative ease of obtaining a small portion of lung tissue may have a research application in helping to elucidate disease mechanisms in the lung.

I gratefully acknowledge the skill of Mr. Ian Jack in modifying the Vim-Silverman needle and in designing and making the new biopsy needle. My thanks are also due to Drs. Laurie, Elmes and Topliss of the Public Health Laboratories for the histological material, and to the Department of Photography of the Public Health Department and my colleagues at the Perth Chest Hospital for allowing me to biopsy some of their patients. I am grateful to the Physician Superintendent for permission to publish the results of this study. 
Patents have been applied for in Australia, the United States of America, and the United Kingdom. The needle is available from the following address at a cost of £A.10 10s.: Medi-Equipment Company, 36 Outram Street, West Perth, Western Australia.

\section{REFERENCES}

Abrams, L. D. (1958). A pleural biopsy punch. Lancet, i, 30.

Craver, L. F., and Binkley, J. S. (1939). Aspiration biopsy of tumors of the lung. J. thorac. Surg., 8, 436.

Gledhill, E. Y., Spriggs, J. B., and Binford, C. H. (1949). Needle aspiration in the diagnosis of lung carcinoma. Amer. J. clin. Path., 19, 235.

Horder, T. J. (1909). Lung puncture: a new application of clinical pathology. Lancet, ii, 1345.

Klassen, K. P., Anlyan, A. J., and Curtis, G. M. (1949). Biopsy of diffuse pulmonary lesions. Arch. Surg., 59, 694.

Lendrum, A. C. (1950). Pulmonary haemosiderosis of cardiac origin. J. Path. Bact., 62, 555.

Leyden, H. (1883). Ueber infectiöse Pneumonie. Dtsch. med. Wschr., 9, 52 .

Manfredi, F., Buckley, C. E., Patrick, R. L., Barry, W. F, and Sieker, H. O. (1960). Lung needle biopsy in the evaluation of diffuse H. O. (1960). Lung needle biopsy in the evaluation
pulmonary disease. Amer. Rev. resp. Dis., 82, 800 .

Miller, F. L. (1960). Percutaneous needle biopsy in clinically inoperable pulmonary tumors. U.S. armed Forces med. J., 11, 838.

Ochsner, A., and DeBakey, M. (1942). Significance of metastasis in primary carcinoma of the lungs. Report of two cases with unusual site of metastasis. J. thorac. Surg., 11, 357.

Sabour, M. S., Osman, L. M., Le Golvan, P. C., and Ishak, K. G. (1960). Needle biopsy of the lung. Lancet, ii, 182 .

Sarin, L. R., and Bhatnagar, L. (1959). Needle biopsy of the lung. Case reports. Indian J. med. Sci., 13, 901.

Scadding, J. G. (1952). Chronic lung disease with diffuse nodular or reticular radiographic shadows. Tubercle (Lond.), 33, 352.

Silverman, I. (1938). A new biopsy needle. Amer. J. Surg., 40, 671.

\section{ADDENDUM}

Up to December 1963 a total of 96 patients, ofㅡㅡ whom 72 had diffuse lung disease, have had needle $\frac{\bar{\Phi}}{\frac{5}{\sigma}}$ biopsy of the lung. The Jack needle has been used $\stackrel{\Phi}{\Phi}$ in the additional 35 patients. It has been slightlyo modified as regards the position and design of the tissue snag, and in its present form is very efficient. A satisfactory biopsy was obtained at the first $\overrightarrow{\vec{\omega}}$ attempt in 23 of the last 27 patients. A little compression of the tissue has occasionally been seen, but to date no serious distortion has occurred: There have been no significant complications. Two. vasovagal episodes occurred but neither patientos lost consciousness. Since then, however, all biopsies $\infty$ have been performed with the patient lying on the side. The incidence of pneumothorax is now about $30 \%$. There were no troublesome air leaks and it has not been necessary to insert an intercostal tube during the last year, probably due to the infrequent necessity of re-inserting the needle $\vec{c}$ on a second occasion. If a second attempt is necessary, it would probably be wise to do this on another occasion.

The Jack needle is currently being tested for synovial biopsy of the larger joints. 